\title{
Estimation of evacuation rates in the field
}

\author{
Rindorf, Anna
}

Published in:

Journal of Fish Biology

Link to article, DOI:

10.1111/j.0022-1112.2004.00450.x

Publication date:

2004

Document Version

Peer reviewed version

Link back to DTU Orbit

\section{Citation (APA):}

Rindorf, A. (2004). Estimation of evacuation rates in the field. Journal of Fish Biology, 65(1), 262-281. https://doi.org/10.1111/j.0022-1112.2004.00450.x

\section{General rights}

Copyright and moral rights for the publications made accessible in the public portal are retained by the authors and/or other copyright owners and it is a condition of accessing publications that users recognise and abide by the legal requirements associated with these rights.

- Users may download and print one copy of any publication from the public portal for the purpose of private study or research.

- You may not further distribute the material or use it for any profit-making activity or commercial gain

- You may freely distribute the URL identifying the publication in the public portal

If you believe that this document breaches copyright please contact us providing details, and we will remove access to the work immediately and investigate your claim 


\title{
Estimation of evacuation rates in the field
}

\author{
A. Rindorf* \\ Danish Institute for Fisheries Research, Charlottenlund Castle, DK2920 \\ Charlottenlund, Denmark. \\ * Tel: +45 339633 59; Fax: +45 339633 33; email: ar@dfu.min.dk \\ RUNNING HEADLINE \\ ESTIMATION OF EVACUATION RATES IN THE FIELD
}


This study presents two methods to calculate evacuation rates based on observed diel changes in occurrence and mean weight of prey in predator stomachs. The methods do not require predators to exhibit prolonged non-feeding periods, but the ingestion of each particular prey type must be restricted to certain diel periods. Data from more than 7500 whiting collected at 5 locations in the North Sea are used to demonstrate the methods. The evacuation rates estimated from field data are similar to laboratory results, though a tendency for estimates to exceed literature values slightly is noted. Bias is introduced if a large proportion of the prey is evacuated completely in the interval between subsequent samples and if significant amounts of other food are present in the stomach together with the prey in question. In conclusion, the methods can be used to supplement laboratory estimates of evacuation rates or provide first estimates for species that are not easily maintained in the laboratory.

Key words: Diel variation, evacuation rates, temperature dependence, whiting. 


\section{INTRODUCTION}

The study of food intake of fish in the wild is often based on a combination of field observations on the amount and type of food in the stomach, and estimates of the rate of evacuation of the stomach content (Hislop et al., 1991; Pillar \& Barange, 1995; Van der Lingen, 1998). Evacuation rates are estimated in separate experiments conducted in the laboratory under standardised conditions. However, these experiments are often difficult to generalise to field conditions. The evacuation of natural prey items such as echinoderms, intact molluscs and crustaceans is rarely examined and the food offered in many cases consists of chopped fish or commercial pellets (e.g. Grove et al., 1985; Hall, 1987; Ruohonen et al., 1997). Further, the evacuation of a meal is affected both by subsequent feeding of the fish and by the quality of the food ingested (Talbot et al., 1984; Grove et al., 1985; Andersen, 2001). These factors are difficult to account for when applying laboratory evacuation rates to field data on stomach contents.

Ideally, laboratory results could be supported by field measurements of evacuation rates. It has, however, proven difficult to obtain direct field estimates (Lockwood, 1980; Köster et al., 1990). Alternatively, the average rate at which stomach content declines during the non-feeding period can be used to estimate evacuation rate of fish, which show pronounced diel feeding patterns (Sainsbury, 1986; Pillar \& Barange, 1995; Pedersen, 2000). Unfortunately, such methods are likely to be biased (Dos Santos \& Jobling, 1995; Andersen, 2001) and can only be applied to species that do not feed throughout the diel cycle. Gadoid fish in the North Sea feed around the clock (Albert, 1995; Mergardt \& Temming, 1997; Adlerstein \& 
Welleman, 2000; Rindorf, 2002) and evacuation rates can not readily be determined from a decrease in the average stomach content of the fish. However, Rindorf (2003) concluded that though whiting (Merlangius merlangus L.) ingested food throughout the diel cycle, the prey types ingested during the night differed from those ingested during the day. Benthic prey such as burrowing invertebrates, crabs and flatfish were ingested at night whereas shrimps, krill, other crustaceans and whiting were ingested during daylight. If these prey types were examined separately, the evacuation rate of each prey could potentially be estimated from field data even though no non-feeding periods occur during the diel cycle.

In this study, two different methods are presented, each of which can be used to estimate evacuation rate from field observations of stomach contents. The methods are based on the assumption that fish caught within 72 hours at a particular location can be considered samples taken from the same population at different times. The objective was to determine whether diel patterns in stomach contents could provide the basis for reliable estimates of evacuation rates. A dataset consisting of stomach contents of more than 7500 whiting caught around the clock at five locations in the North Sea were used to test the two methods. Whiting has been well studied in the laboratory and substantial literature on evacuation rates of this species exists (Jones, 1974; Seyhan \& Grove, 1998; Andersen, 1998, 1999, 2001 and references therein). It is therefore well suited for the comparison of field and laboratory estimates of evacuation rates. 


\section{METHODS}

The contents of fish stomachs are notoriously variable, and the variation is generally poorly described by simple statistical distributions. As a result, Pennington et al. (1980) suggested using the delta distribution to estimate mean and variance of the stomach contents. The delta distribution is composed of two distributions: A probability, $p$, that the stomach contains food, and a distribution of the total weight of the food in the stomachs where food is found. Following this idea, Stefánsson and Pálsson (1997) formulated a delta distribution of the weight of the stomach contents and showed that the analysis of stomach contents can be divided into two separate analyses. One analysis examines the probability that a stomach is non-empty, and another the weight of the stomach contents in non-empty stomachs. The division of the analysis into prey occurrence and total prey weight in stomachs where the prey is found provides the opportunity to estimate evacuation rates by two new methods.

\section{CALCULATION OF FIELD EVACUATION RATES}

The evacuation of whiting stomachs is adequately described by the so-called square root model (Andersen, 1998):

$$
d S d t^{-1}=-\rho S_{0}^{0.5}
$$

or

$$
S_{t}=\left\{\begin{array}{cl}
S_{0}\left(1-0.5 \rho t S_{0}^{-0.5}\right)^{2}, & t \leq 2 S_{0}^{0.5} \rho^{-1} \\
0 & t>2 S_{0}^{0.5} \rho^{-1}
\end{array}\right.
$$

where $S_{0}$ is the weight of the prey prior to evacuation $(t=0), S_{t}$ is the weight of the stomach content (both in grammes) at time $t$ (in hours), and $\rho$ is a constant, from 
hereon referred to as the evacuation rate. Rearranging (1), the evacuation rate can be estimated as

$$
\rho=2 t^{-1}\left(S_{0}^{0.5}-S_{t}^{0.5}\right), \quad S_{t}>0
$$

Note that the model applies only to periods in which no ingestion takes place. If such a period occurs for a particular prey, estimates of $S_{0}^{0.5}$ and $S_{t}^{0.5}$ (and thus $\rho$ ) can be obtained by sampling stomachs. The delta distribution provides the opportunity to calculate estimates of $S_{0}^{0.5}$ and $S_{t}^{0.5}$ by two different methods. The first method (Method I) attempts to minimise the bias introduced on estimated evacuation rates when the particular prey does not occur in all stomachs. The second method (Method II) takes advantage of the information provided by a pronounced drop in occurrence at some point of the diel cycle.

\section{Method I}

Several problems arise when evacuation rates are estimated from field samples. Firstly, it is a well known problem that empty stomachs should not be included as they bias the estimated evacuation rate (Bromley, 1994). The problem is evident in the following theoretical example: Assume that we have 10 fish of which 5 have fed. The average stomach content of the fish which have fed decreases from 1 to $0.9 \mathrm{~g}$ during the first hour of the experiment. The evacuation rate is then $\rho=2\left(1^{0.5}-0.9^{0.5}\right)=0.10$. However, if the evacuation rate is calculated as an average of all fish, it is only $\rho=2\left(\left(5 \cdot 0^{0.5}+5 \cdot 1^{0.5}\right) 10^{-1}-\left(5 \cdot 0^{0.5}+5 \cdot 0.9^{0.5}\right) 10^{-1}\right)=0.05$ As empty stomachs are frequently recorded in the field, the average stomach content of all fish caught is not suitable for the estimation of evacuation rates. Instead, an 
improved estimate can be obtained by examining the average weight of prey only in the stomachs where it occurs. Hence, $S_{0}$ becomes equal to the mean weight of the prey in the stomachs where it occurred at time $0 . S_{t}$ is then the mean weight of the prey after $t$ hours of evacuation. If the prey has been evacuated completely from some of the stomachs in the time interval, $S_{t}$ must be corrected for this. Assuming the weight of the prey to be zero in the stomachs where it is not recorded, $S_{t}=p_{t} p_{0}^{-1} E\left(w_{t}\right)$

where $p_{t}$ is the proportion of stomachs which contain the prey at time $t, p_{t} p_{0}^{-1}$ is the proportion of the stomachs containing the prey at time 0 that still contain the prey at time $t$ and $E\left(w_{t}\right)$ is the mean weight of the prey in the stomachs where it occurred at time $t$. Evacuation rate can then be estimated as

$\rho=2 t^{-1}\left(\left(E\left(w_{0}\right)\right)^{0.5}-\left(p_{t} p_{0}^{-1} E\left(w_{t}\right)\right)^{0.5}\right)$

using the same notation as above.

Method II

Evacuation rate can also be estimated without encountering the problems of averaging over empty stomachs at all. This is done by utilising the information in the weight distribution of the prey at time 0 and the difference in the probability that the prey occurs at time 0 and time $t$. If the occurrence of a prey drops by e.g. 50\% from time 0 to $t$, this must correspond to complete evacuation of $50 \%$ of the prey present at time 0 . The first prey to be evacuated completely will be the smallest prey. Larger prey will still be present at time $t$, albeit with a lower weight than at time 0 . If $50 \%$ of the prey weighed 1 gram or less at time 0 the maximum weight of prey which was 
evacuated completely in $t$ hours would be $1 \mathrm{~g}$. Thus, for the time interval $t$ evacuation rate can be estimated by inserting the values $S_{0}=1$ and, ideally, $S_{t}=0$ into equation (2). However, as prey cannot usually be identified during the last stages of digestion, $S_{t}$ is more reasonably set at the estimated weight at which the prey can no longer be recognised. Thus, evacuation rate can be estimated by calculating the largest drop in occurrence and from this estimating the maximum weight evacuated. The maximum weight is estimated from the accumulated distribution of weights in the stomachs where the prey was present at time 0 (Fig. 1).

\section{DATA EXAMPLE}

\section{Collection of data}

Details of the sampling procedure can be found in Rindorf (2002). Briefly, whiting were caught by bottom trawling at 5 locations in the North Sea in early September. One haul was taken every 4 hours in a total of between 48 and 72 hours at each location. The bottom temperature was $16.7,13.7,10.6,8.2$ and $8.6{ }^{\circ} \mathrm{C}$ at locations 1 to 5 , respectively. Stomachs of whiting were collected by length stratified sampling, collecting 50 stomachs from each $5 \mathrm{~cm}$ group when available. In total, stomachs from 7738 whiting (length $20 \mathrm{~cm}$ to $35 \mathrm{~cm}$ ) were examined. To assure a reasonable number of observations for each combination of time, location and size of the predator, the predators were grouped in the length intervals $20-24.9 \mathrm{~cm}, 25-29.9$ $\mathrm{cm}, 30-34.9 \mathrm{~cm}$. The stomachs of whiting, which did not show signs of regurgitation, were frozen individually as quickly as possible. In the laboratory, the recognizable contents were assigned to species (fish) or major groups: 'shrimps', 'crabs', 'krill', 
‘other benthic invertebrates’ (mainly polychaetes, echinoderms, molluscs, hermit crabs and Norway lobster (Nephrops norvegicus L.)) and ‘other crustaceans' (mainly amphipods and unidentifiable crustacean parts). The small number of prey in pristine condition which had presumably been eaten in the trawl was excluded from analyses.

\section{DATA ANALYSES}

Differences in occurrence and weight can be tested separately for statistical significance using generalised linear models (McCullaugh \& Nelder, 1989; Stefánsson \& Pálsson, 1997). The advantage of this is that samples, which do not differ significantly, can be joined prior to the estimation of average occurrence and weight of prey. Joining samples results in estimates based on larger sample sizes and thus with lower standard error of the mean. Generalised linear models are applicable for testing as long as the number of observations within each statistical cell (i.e. combination of predator size group, location and time) is greater than 5 (McCullaugh \& Nelder, 1989). The probability that a stomach taken from a fish caught at a given time and location contains the prey groups recorded has been analysed in detail by Rindorf (2003). Briefly, the occurrence of bottom dwelling prey (dab (Limanda limanda L.), 'crabs' and 'other benthic invertebrates') was found to be highest in the night time, whereas 'krill', 'shrimps', 'other crustaceans' and 'whiting' occurred mostly in stomachs sampled during the day time (Fig. 2). No significant diel variation was found in the occurrence of the remaining prey groups. As the estimation of evacuation rates by method II requires diel differences in occurrence of the particular prey types, evacuation rates were only estimated for the prey where these differences were significant. Though the occurrence of dab varied with time of day (Rindorf, 
2003), on average this prey was weighed in less than 5 stomachs per combination of predator length group, location and time of day. The number of observations required to perform reliable tests in generalised linear models was thus not obtained (McCullaugh \& Nelder, 1989) and dab was excluded from further analyses. Hence, the prey groups included in the analyses below were 'crabs', 'other benthic invertebrates', 'krill', 'shrimps', 'other crustaceans' and 'whiting'.

Analysis of total weight of each prey group in the stomachs

Generalized linear models were used to test for significant differences in mean weight of each prey group (Stefánsson \& Pálsson, 1997). The weight of a particular prey group in a stomach containing this prey, $w$, was assumed to be gamma distributed and analysed in the generalised linear model:

$$
\ln \left(w_{l o c, t, L, i}\right)=a_{l o c}+b_{t}+c_{L}+a b_{l o c, t}+a c_{l o c, L}+b c_{t, L}+\varepsilon_{i}
$$

where loc denotes location, $t$ is time of day (GMT, 6 times of day sampled), $L$ is predator length group, $i$ is sample number, $a, b, c, a b, a c$ and $b c$ are constants within indices to be estimated in the model and $\varepsilon_{i}$ is a gamma distributed random error term. This model is comparable to an analysis of variance of gamma distributed data. The data were examined for trends in prey weight over the sampling period, but none were found. The second order interaction term between predator length, location and time of day was not included in the model as the required number of observations within each combination (5) was not obtained for every 4-hour interval for all combinations of prey group, predator length and location. However, the second order effect was tested on a subset of the data, consisting only of predator length groups and location 
combinations for which more than 5 prey samples were weighed at all times of day. The effect was not significant for any of the prey groups.

The factors that did not have a significant effect on the mean weight of prey (F-test, $\mathrm{P}<0.05$ ) were eliminated from the model and the reduced model was used to estimate mean weight of each prey around the clock, $\hat{w}_{j, t}$, for each location and predator length group. If no significant differences between locations or length groups were found, one mean weight was thus estimated for all locations or length groups, respectively. Joining samples which were not statistically different was considered a valid approach in the present study as the number of observations in all cases was large and the risk of committing a type I error hence small. However, the methods suggested for the estimation of evacuation rates do not depend on whether samples are joined but merely on the accuracy of the estimated mean weight and occurrence.

Field estimates of evacuation rates: Method I

The probability that a stomach contained a given prey group, $p_{j, t}$, around the clock for all predator length groups and locations was given by Rindorf (2003) and the mean weight of the prey found was estimated from equation (4) after removing insignificant effects. As the interval between consecutive sampling points was $4 \mathrm{~h}$, evacuation rate, $\rho$ I, of prey $j$ can be estimated for each time interval $t$ to $t+4$ by (Eq. 3 ) $\rho_{I, j, t}=0.5\left(\hat{w}_{j, t}^{0.5}-\left(p_{j, t+4} p_{j, t}^{-1} \hat{w}_{j, t+4}\right)^{0.5}\right)$

Evacuation rate was calculated whenever $\hat{w}_{j, t}$ exceeded $p_{j, t+4} p_{j, t}^{-1}\left(\hat{w}_{j, t+4}\right)$. However, two exceptions were made: Firstly, when $p_{j, t+4} p_{j, t}^{-1}\left(\hat{w}_{j, t+4}\right)$ was very low $(<0.01 \mathrm{~g})$, the 
prey was effectively missing and as it was not known for how long it had been so.

Secondly, a low difference $(<0.01 \mathrm{~g})$ between $\hat{w}_{j, t}$ and $p_{j, t+4} p_{j, t}^{-1}\left(\hat{w}_{j, t+4}\right)$ renders the estimate of $\rho_{I}$ uncertain. In these two cases, no estimate of evacuation rate calculated.

Two final estimates of evacuation rates were calculated. First, $\rho_{\text {Ia }}$ was calculated as the average of all $\rho_{I}$ at a given location and predator length. If ingestion only took place in periods where $p_{j, t+4} p_{j, t}^{-1}\left(\hat{w}_{j, t+4}\right)$ exceeded $\hat{w}_{j, t}$, this average will provide the best estimate of evacuation rate. A second estimate of evacuation rate, $\rho_{I b}$, was calculated at the time of the maximum (positive) difference between $\hat{w}_{j, t}$ and $p_{j, t+4} p_{j, t}^{-1}\left(\hat{w}_{j, t+4}\right)$. If some minor ingestion takes place at all times of day but one, $\rho_{I b}$ provides the best estimate of evacuation rate. Note that $\rho_{I b}$ is likely to be positively biased as large values will be assumed to be true rather than caused by random error.

Field estimates of evacuation rates: Method II

The time of the maximum drop in the proportions of stomachs containing each prey from one time of day to the next was identified from the model predictions given in Rindorf (2003). The percent decrease in occurrence, $\Delta o \%$, was then calculated as $\Delta o \%=100\left(p_{t}-p_{t+4}\right) p_{t}^{-1}$

where $t$ is the sampling time prior to the greatest drop in occurrence. To determine the maximum weight of prey which had been evacuated in the 4-hour interval, $w(\Delta o \%)$, the cumulated weight distribution of the prey was calculated. After allocating the prey to $0.1 \mathrm{~g}$ intervals, the weight below which $\Delta o \%$ of the prey was recorded was calculated by linear interpolation of the cumulated distribution. So was then assumed 
to equal $w(\Delta o \%)$. As a prey cannot be determined to prey group in the last stages of digestion, the method requires the selection of some lower limit of detection. In the present study, this was set to $25 \%$ of $w(\Delta o \%)$ as this is a likely limit of recognition for the untrained eye (Andersen, pers. comm.). $S_{4}$ was hence equal to $0.25 w(\Delta o \%)$. The accumulated weight distribution was calculated in cases where prey from more than 10 stomachs had been weighed at the time just prior to the greatest drop in occurrence. If the general linear models of weight of the prey did not reveal significant differences between length groups, locations and/or time of day, a common cumulate distribution of the prey was calculated for all predator length groups, locations and/or times of day, respectively.

Calculation of size and temperature specific evacuation rate, $\rho \mathrm{LT}$

The evacuation rate of gadoids can be described by the function

$$
\rho=\rho_{L T} L^{\lambda} e^{\delta T}
$$

where $\rho_{L T}$ is a prey specific constant, $L$ is predator length $(\mathrm{cm}), T$ is temperature $\left({ }^{\circ} \mathrm{C}\right)$ and $\lambda=1.44$ and $\delta=0.078$ (Andersen, 1999). The temperature and size specific evacuation rate, $\rho_{L T}$, has been estimated for a number of prey types in the laboratory (Andersen 1999, 2001). To compare the evacuation rates found in this study to literature values, $\rho_{L T}$ of each prey was calculated by assuming the relationship given in (4). One value of $\rho_{L T}$ was calculated for each location and predator length and the average for each prey calculated. 
Estimation of the effect of size and temperature on evacuation rate

Although the relationship between evacuation rate and temperature and predator length has been shown to describe laboratory estimates accurately, the parameter values could theoretically differ in a field situation. The parameters in the general linear model

$\ln \left(\rho_{l o c, L, j}\right)=\ln \rho_{L T}+\lambda \ln L+\delta T_{l o c}+v_{j}$

were therefore estimated. $\rho_{l o c, L, j}$ is the evacuation rate estimated by the above methods in the $j^{\text {th }}$ combination of location, time of day and predator length, $\rho_{L T}, \lambda$ and $\delta$ are parameters to be estimated, and $v_{j}$ is a normal distributed error term. One model was estimated for each prey group and each method. The parameters were only estimated in the cases where more than 10 values of $\rho$ could be estimated (the prey groups 'crabs', ‘other benthic invertebrates' and 'other crustaceans' for methods Ia and Ib, and 'krill' and 'other benthic invertebrates' for method II) and the parameter estimates of the different prey groups were tested for significant differences (F-test). The length of the predator was set equal to the midpoint of the length group.

Bias

The calculation of $\rho_{\text {I }}$ from mean weights rather than individual fish may introduce a bias in the estimates (Andersen, 2001). To investigate the extent of this bias, a theoretical exercise was performed. The observed distribution of weights of prey in stomachs where the prey was present was calculated for all prey groups. One distribution was calculated for each location and predator size group. The weight of 
each prey after 4 hours of evacuation was then calculated by (1) $(t=4)$. Evacuation rate was set to $\rho=0.00038 L^{1.44} e^{0.078 T}$

The constant 0.00038 was calculated as the value for prey without exoskeleton and an energy density of $4.2 \mathrm{Kjg}^{-1}$ wet weight as described by Andersen (1999). If the weight of the prey in the stomachs after four hours of evacuation was below $25 \%$ of the original weight, prey would no longer be recognized and the weight was recorded as zero. The average weight before and after four hours of evacuation was calculated as the observed mean weight and the predicted mean weight after applying eq. (1), respectively. The estimated evacuation rate, $\rho_{a}$, was calculated for each prey by inserting the observed mean weight and the predicted mean weight at $t=4$ in eq. (3) and the bias calculated as $\left(\rho_{a}-\rho\right) \rho^{-1}$

If the stomach contains other food than the particular prey, evacuation is affected and the estimated evacuation rate may be further biased (Andersen, 2001). The weight of prey present after four hours of evacuation in the presence of other food can be described by

$$
S_{p, 4}=S_{p, 0}\left(1-2 \rho\left(S_{p, 0}+S_{o f, 0}\right)^{-0.5}\right)^{2}
$$

where

$S_{p, 0}$ and $S_{o f, 0}$ are the weight of prey $p$ and the weight of other food at time 0 , and $\rho$ is the common evacuation rate of the two prey (Andersen, 2001). Rearranging (6), the evacuation rate can be calculated as

$$
\rho=0.5\left(S_{p, 0}^{0.5}-S_{p, 4}^{0.5}\right)\left(\left(S_{p, 0}+S_{o f, 0}\right) S_{p, 0}^{-1}\right)^{0.5}
$$


As the estimate of $\rho$ calculated without taking the presence of other food into account is (inserting $t=4$ in (2))

$\rho_{b}=0.5\left(S_{p, 0}^{0.5}-S_{p, 4}^{0.5}\right)$

the bias of ignoring other food is

$\left(\rho_{b}-\rho\right) \rho^{-1}=\left(S_{p, 0}\left(S_{p, 0}+S_{o f, 0}\right)^{-1}\right)^{0.5}-1$

The percentage by weight of each prey group in the stomachs where it was found was determined at each location, and the bias calculated by the above formula.

Statistical analyses

All statistical analyses were performed using SAS ${ }^{\circledR}$ version 8 for Windows ${ }^{\circledR}$. The shape parameters of the generalised linear models were estimated by the Pearson statistic. Factors not having a significant effect at the 5\% level (F-statistic) were eliminated from the models.

\section{RESULTS}

OCCURRENCE AND WEIGHT OF EACH PREY GROUP IN THE STOMACHS

Significant diel variation in the weight of prey in the stomachs was found for all prey (Table I) and selected examples of observations and model fit as a function of time of day can be seen in Fig. 3. The models of weight of prey explained between 4 
and $57 \%$ of the total deviance (Table I). The diel pattern in weight of 'other crustaceans' and 'other benthic invertebrates' did not differ between locations, and the daily mean weight of ‘other benthic invertebrates’ did not vary significantly between the five locations. The diel pattern in mean weight generally resembled the pattern in occurrence of each prey. Both weight and occurrence of 'krill' in the stomachs decreased from 0700 to 1100 hours and again from 2300 to 0300 hours, and both increased for 'shrimps' (locations 2 and 5) and 'other crustaceans' through the day

(Figs. 2 and 4). The pattern in weight of 'crabs' was erratic, though the weight generally increased during darkness and exhibited an additional peak at either 1100 or 1500 hours. The additional peak was caused by one (locations 2 and 3) or two (location 4) crabs with a weight greater than $2 \mathrm{~g}$. The weight of 'other benthic invertebrates' increased from 2300 to 0700 hours followed by a gradual decrease until 2300 hours whereas occurrence of this prey decreased from 0700 to 1900 hours.

Prey weight increased with predator length in all cases where the difference between length groups was significant, and the increase was proportional to predator weight for the prey groups ‘crabs’ and 'other benthic invertebrates', whereas differing patterns were found for the remaining prey. Only the prey 'whiting', 'crabs' at location 2 and 'shrimps' at location 5 were found to weigh more than $1 \mathrm{~g}$ in total for a predator of $27.5 \mathrm{~cm}$ (Fig. 4).

\section{EVACUATION RATES}

The square root model could not be rejected by the present data (Fig. 5). However, 'crabs’ appeared to be evacuated extremely quickly from stomachs 
containing more than $1.3 \mathrm{~g}$ of this prey. These data points corresponded to the peaks in mean weight of 'crabs' in the stomach at locations 2, 3 and 4 that were caused by one or two large crabs. As the peaks were based on so few observations, the data from location 2 at 1100 hours and locations 3 and 4 at 1500 hours were not included in the estimation of evacuation rates.

Evacuation rates calculated by the two methods were generally comparable (Table II, Figs. 6 and 7). Further, they were highly and significantly correlated (all correlations $>0.75(\mathrm{P}<0.001))$. The estimates derived by methods Ib and II were in no case significantly different from proportional to the estimate by method Ia (slope of the linear relationship not significantly different from 1). However, methods Ib and II produced estimates approximately 50\% greater than those produced by method Ia. Method II provided slightly higher estimates than method Ib (Table II).

Evacuation rate increased with temperature for the prey groups 'whiting', 'krill' and 'other benthic invertebrates' whereas no trend in evacuation rate with temperature could be detected for the remaining prey (Figs. 6 and 7). The rate increased with predator size for all prey groups though the difference was small for 'krill' (Fig. 6). The effect of predator length on evacuation rate, $\lambda$, was estimated to be 1.21 and 1.48 using evacuation rates calculated by methods Ia and Ib, respectively (Table III). The parameter did not vary significantly between prey types. The temperature effect, $\delta$, varied significantly between prey groups and a significant negative effect was found for 'crabs' (Methods Ia and Ib) whereas significantly positive values were estimated for 'krill' (Method II) and 'other benthic invertebrates' 
(Method Ib)(Table III). The estimates of $\rho_{L T}$ differed significantly between prey groups for all three methods (data not shown).

BIAS

Using mean weights biased the evacuation rates negatively, thus making the rates seem smaller than was actually the case (Fig. 8A). The amount of negative bias was positively correlated to the proportion of prey which had a weight smaller than $25 \%$ of the initial weight after four hours of digestion, i.e. had been evacuated beyond recognition (correlation $=0.41, \mathrm{P}=0.036, \mathrm{n}=26$ (one data point for each location and prey)). The bias was below $15 \%$ for most of the prey groups (mean $14 \%$ ). Note that the bias introduced by using mean weights does not affect evacuation rates calculated by method II.

Mixed meals severely biased the estimated evacuation rate towards lower values (Fig. 8B and C). Only the prey groups 'whiting' and 'other benthic invertebrates' were estimated to be biased by less than $15 \%$ on average. The remaining prey groups exhibited high bias at least at one of the locations.

\section{DISCUSSION}

The proposed methods produced estimates of evacuation rates which were largely consistent with literature values. The relationship between predator length and evacuation rate was furthermore remarkably close to that found in laboratory 
experiments, as the estimated values of $\lambda$ were not significantly different from the value of 1.44 ( \pm 0.3 ) found by Andersen (1999). Further, the mean effect of temperature on evacuation rate of 'krill' and 'other benthic invertebrates' determined by method II was 0.079 , which is virtually identical to the $0.078( \pm 0.01)$ estimated in the laboratory (Andersen, 1999). The methods therefore appear to be useful supplements to laboratory estimates of evacuation rates.

The square root evacuation model appeared to fit the data well apart from a few data points for 'krill' and larger 'crabs' (Fig. 5). The problems encountered were most likely caused by small sample sizes, which gave single large prey weights and low occurrences a large influence on mean weights. It was attempted to limit such random errors by first testing whether the observations differed significantly between times of day, predator length groups and locations using generalised linear models. This achieves a lower standard variation around the mean in cases where samples are not significantly different and is a commonly applied procedure (e. g. McCullaugh \& Nelder 1989; Magnusson \& Aspelund, 1997; Mallekh et al., 1998; Bell et al., 1999). In biological terms, joining samples from different groups before estimating the mean weight of prey corresponds to assuming that predators through either active selection or by being exposed to similar prey densities succeeded in maintaining on average the same amount prey in the stomach. Such assumptions should not be made carelessly, as lack of statistical difference between samples may be caused by low sample size or large variation within samples rather than actual lack of difference (a type I error). In the present study, the number of stomachs sampled was very large as was the number of stomachs containing prey in each category and hence the risk of committing a type I error was small. Furthermore, there was no indication of an effect of joining samples 
through eliminating parameters from the generalised linear model on the estimated evacuation rates. The rate estimated for the prey for which the greatest number of parameters were retained in the model ('crabs') was thus further away from literature values than those of the three other prey groups which possess exoskeletons and for which a greater degree of model reduction was performed ('krill', 'shrimps' and 'other crustaceans'). In any event, the statistical elimination procedure is not a requirement for the estimation of evacuation rates. These could also be estimated directly from observed occurrence and prey mean weight at different sampling times if joining samples was considered inappropriate.

The methods are biased to a varying degree by a number of factors. Method Ib is likely to be positively biased due to the examination of only the greatest drop in mean weight, whereas method Ia is likely to produce too low estimates if the predator ingests minor amounts of prey during the period in which mean weight decreases. In most cases, the best estimate is likely to be somewhere between the estimates of the two methods. Method II is presumably slightly positively biased in all cases as it relies on the maximum drop in occurrence. Negative bias is introduced both by using mean weights to calculate evacuation rates and by ignoring the effect of other prey in the stomach. The predicted mean weight bias acting on methods Ia and Ib averaged $14 \%$ and increased with the proportion of stomachs from which the prey was completely evacuated in the sampling interval. Mean weight bias should not influence on method II, and method Ib should hence provide estimates of $86 \%$ of method II on average. Nevertheless, the observed difference between method Ib and II was less than 5\%. Similarly, though substantial negative bias was predicted for all prey types from other prey in the stomach, the only prey for which $\rho_{L T}$ was estimated to be lower 
than in laboratory experiments was 'krill' (laboratory estimate 0.00039 (Andersen, 1999), this study $0.00017-0.00031$ ). There was thus theoretical evidence of negative bias, but the bias could rarely be detected in the field estimates of evacuation rates.

A prerequisite to using stomach samples to investigate diel feeding patterns and daily food intake is the assumption that predators sampled at a particular location have similar feeding histories. This assumption is supported by the general consistency between stomach samples taken at the same location within a matter of days (Adlerstein \& Welleman, 2000; Rindorf, 2003) and is a common implicit assumption in studies based on stomach contents (e.g. Lockwood, 1980; Sainsbury, 1986; Seyhan \& Grove, 1998; Adlerstein \& Welleman, 2000; Darbyson et al., 2003). Similarity in feeding history requires that the predators on average have been exposed to the same available food and have reacted to this in a similar way, acknowledging that random variation around both food encounter rates and predator reaction may occur. An instant change in prey availability would thus not invalidate the present method and neither would a large variance between the intake of individuals. Large variance merely implies that a greater number of stomachs must be sampled to estimate the mean contents accurately. However, if the feeding history of the population fished was instantaneously altered due to e.g. total emigration of the population present and total immigration of a new population, the methods could not be used and the estimates of evacuation rates would be a result of random variation between the two populations. Daily migrations in an out of an area have been demonstrated for certain reef fish species (Hobson, 1968). However, these migrations appeared to be performed by the entire population rather than two subpopulations exchanging positions. Apparent exchange of two populations could also occur if the 
density of predators is locally depleted through repeated trawling, and the predators caught in the end of the sampling interval represented fish with different feeding histories migrating into the area. Such problems will most likely to invalidate the use of the methods for estimation of evacuation rates of rapidly migrating populations. In the case of the data used here, Rindorf (2003) analysed the correlation between prey occurrence and predator catch rate to determine if the occurrence of prey could be linked to the presence of a greater number of predators possibly derived from a migrating subpopulation with a different food composition or whether trends in the catch rates of predators could be detected, indicating local depletion and subsequent migration of predators into the area. Neither trends in catch rates nor any significant correlation between catch rates and occurrence of prey could be detected (Rindorf, 2003). There was thus no evidence to suggest that the predators in the present study belonged to more than one population at a given location.

The evacuation rate of the prey groups 'krill', 'whiting' and 'other benthic invertebrates' increased with temperature. The values of $\delta$ estimated from methods Ib and II for 'other benthic invertebrates' (0.048 and 0.042) and 'krill' (0.14) were close to the 0.078 found in the laboratory (Andersen, 1999). In contrast, there was little evidence of a relationship between $\rho$ and temperature for the prey groups 'shrimps', 'crabs' and 'other crustaceans' and the effect of temperature on the evacuation of prey with hard exoskeletons may be less than the effect on soft prey. The relationship between evacuation rate and predator size was generally clearer, with estimates of $\lambda$ falling very close to the value of 1.44 given by Andersen (1999)(Table III). The difference in $\lambda$ between prey with hard exoskeleton and soft prey detected by Andersen (1999) was not seen here. However, of the prey having hard exoskeletons, 
only 'crabs' and 'other crustaceans' were used to estimate $\lambda$ and the random variation around the relationship may have obscured the relatively minor effect of the exoskeleton.

The tendency for field estimates of evacuation rates to exceed laboratory estimates appears to be a general phenomenon. Thus, Seyhan and Grove (1998) and Pedersen (2000) estimated evacuation rate of whiting from a decrease in observed stomach content, and derived estimates in the order of 2 to 13 and 4 to 21 times laboratory estimates, respectively. In flatfish, Basimi and Grove (1985) reported field estimates of plaice (Pleuronectes platessa L.) evacuation rates in excess of $140 \%$ of rates determined in aquaria. Dos Santos and Jobling (1995) found that the evacuation of prawn from cod (Gadus morhua L.) stomachs appeared to be lower in the laboratory, perhaps due to greater evacuation rate in naturally feeding cod. Similarly, Albert (1995) estimated field evacuation rates of haddock (Melanogrammus aeglefinus L.), and thereby total consumption, to be higher than literature values.

The methods presented here have an advantage over existing methods as evacuation rates can be estimated even if the predator is ingesting food around the clock as long as the particular prey type is not ingested for at least a shorter period of the diel cycle. This renders the methods applicable to predators who do not exhibit the prolonged non-feeding periods required by other methods (Sainsbury, 1986). In this study, four hour periods were used, but this could easily be altered by changing the sampling design. If the predator is known to feed on a particular prey during day and another during night, it may be sufficient to sample the predators at dawn and dusk. On the other hand, shorter intervals may be required for prey that is ingested 
throughout most of the diel cycle. The estimates of evacuation rates were surprisingly close to laboratory values, indicating that the methods do indeed provide consistent estimates of evacuation rates. They do not appear to be biased to the extent that simpler methods may be (e.g. Seyhan \& Grove, 1998; Pedersen, 2000). To achieve the best possible estimates, it is important that the prey occurs in a reasonable number of stomachs, preferably not together with other prey, and that the predator is sufficiently common to avoid problems with small sample sizes. Furthermore, it is crucial that the predators are sampled from the same local population, i.e. in the same location and within a short time interval. The drawback of the method is clearly the need for sampling of large numbers of stomachs, in particular if narrow confidence intervals of the estimates are desired. Such intervals were not calculated here, but estimating them for Methods Ia and Ib is straightforward, as the variance of both occurrence and mean weight is readily derived. In conclusion, the methods could provide useful supplements to laboratory estimates of evacuation rates and even estimates of evacuation rates of fish, which are not easily maintained in aquaria.

I thank Prof. Gislason and P. Degnbol, who collected the stomach data and placed them at my disposition, A. D. Hansen who worked up the stomach contents so thoroughly and N. G. Andersen for valuable discussions on both methods and results. This study was partly funded by a grant from the Danish Ministry of Food, Agriculture and Fisheries to the project 'Development of improved models of fisheries impact on marine fish stocks and ecosystems' (FIFOF-DFU-1). The research was supported by the SLIP research school under the Danish Network for Fisheries 
and Aquaculture Research (www.fishnet.dk) financed by the Danish Ministry for Food, Agriculture and Fisheries and the Danish Agricultural and Veterinary Research Council.

\section{REFERENCES}

Adlerstein, S. A. \& Welleman, H. C. (2000). Diel variation of stomach contents of North Sea cod (Gadus morhua) during a 24-h fishing survey: an analysis using generalized additive models. Canadian Journal of Fisheries and Aquatic sciences 57, 2363-2367.

Albert, O. T. (1995). Diel changes in food and feeding of small gadoids on a costal bank. ICES Journal of Marine Science 52, 873-885.

Andersen, N. G. (1998). The effect of meal size on gastric evacuation in whiting. Journal of Fish Biology 52, 743-755. doi: 10.1006/jfbi.1997.0617

Andersen, N. G. (1999). The effects of predator size, temperature, and prey characteristics on gastric evacuation in whiting. Journal of Fish Biology 54, 287-301. doi: 10.1006/jfbi.1998.0865. 
Andersen, N. G. (2001). A gastric evacuation model for three predatory gadoids and implications of using pooled field data of stomach contents to estimate food rations. Journal of Fish Biology 59, 1198-1217. doi: 10.1006/jfbi.2001.1731

Basimi, R. A. \& Grove, D. J. (1985). Estimates of daily food intake by an inshore population of Pleuronectes platessa L. off eastern Anglesey, North Wales. Journal of Fish Biology 27, 505-520.

Bell, G. W., Buckel, J. A. \& Stoner, A. W. (1999). Effects of alternative prey on cannibalism in age-1 bluefish. Journal of Fish Biology 55, 990-1000. doi: 10.1006/jfbi.1999.1102

Bromley, P. J. (1994). The role of gastric evacuation experiments in quantifying the feeding rates of predatory fish. Reviews in Fish Biology and Fisheries 4, 3666.

Darbyson, E., Swain, D. P., Chabott, D. \& Castonguay, M. (2003). Diel variation in feeding rate and prey composition of herring and mackerel in the southern Gulf of St Lawrence. Journal of Fish Biology 63, 1235-1257. doi: 10.1046/jfbi.1095-8649.2003.00247.x.

Dos Santos, J. \& Jobling, M. (1995). Test of a food consumption model for the Atlantic cod. ICES Journal of Marine Science 52, 209-220.

Grove, D. J., Loizides, L. G. \& Nott, J. (1978). Satiation amount, frequency of feeding and gastric emptying rate in Salmo gairdneri. Journal of Fish Biology 12, 507-516.

Grove, D. J., Moctezuma, M. A., Flett, H. R. J., Foott, J. S., Watson, T. \& Flowerdew, M. W. (1985). Gastric emptying and the return of appetite in juvenile turbot, 
Scophthalmus maximus L., fed on artificial diets. Journal of Fish Biology 26, 339-354.

Hall, S. J. (1987). Maximum daily ration and the pattern of food consumption in haddock, Melanogrammus aeglefinus (L.), and dab, Limanda limanda (L.) Journal of Fish Biology 31, 479-491.

Hislop, J. R. G., A.P. Robb, M. A. Bell \& Armstrong, D. W. (1991). The diet and food consumption of whiting (Merlangius merlangus) in the North Sea. ICES Journal of Marine Science 48, 139-156.

Hobson, E. S. (1968). Predatory behavior of some shore fishes in the Gulf of California. U.S. Fish and Wildlife Services, Research report 73. Bureau of Sport Fisheries and Wildlife, Washington.

Hopkins, T. E. \& Larson, R. J. (1990). Gastric evacuation of three food types in the black and yellow rockfish Sebastes chrysomela (Jordan and Gilbert). Journal of Fish Biology 36, 673-682.

Jones, R. (1974). The rate of elimination of food from the stomachs of haddock Melanogrammus aeglefinus, cod Gadus morhua, and whiting Merlangius merlangus. Journal du Conseil International pour l'Exploration de la Mer 35, 225-243.

Köster, F. W., Schober, W., Korves, A. \& Schneider, R. (1990). Tank experiments on board: a useful tool for the estimation of stomach evacuation rates? ICES Council Meeting 1990/G:34

Lockwood, S. J. (1980). The daily food intake of 0-group plaice (Pleuronectes platessa L.) under natural conditions. Journal du Conseil International pour l'Exploration de la Mer 39, 154-159. 
Magnússon, K. G. \& Aspelund, T. (1997). A model for estimating meal frequency and meal size from stomach data with an application to Atlantic cod (Gadus morhua) feeding on capelin (Mallotus villosus). Canadian Journal of Fisheries and Aquatic Sciences 54, 876-889.

Mallekh, R., Lagardere, J. P., Begout Anras, M. L. \& Lafaye, J. Y. (1998). Variability in appetite of turbot, Scophthalmus maximus, under intensive rearing conditions: the role of environmental factors. Aquaculture 165, 123-138.

McCullaugh, P. \& Nelder, J. A. (1989). Generalized linear models. Monographs on Statistics and Applied Probability No. 37, $2^{\text {nd }}$ edn. London: Chapman \& Hall. Mergardt, N. \& Temming, A. (1997). Diel pattern of food intake in whiting (Merlangius merlangus) investigated from the weight of partly digested food particles in the stomach and laboratory determined particle decay functions. ICES Journal of Marine Science 54, 226-242.

Pedersen, J. (2000). Food consumption and daily feeding periodicity: comparison between pelagic and demersal whiting in the North Sea. Journal of Fish Biology 57, 402-416. doi: 10.1006/jfbi.2000.1316.

Pedersen, J., \& Hislop, J. R. G. (2001). Seasonal variations in the energy density of fishes in the North Sea. Journal of Fish Biology 59, 380-389. doi: 10.1006/jfbi.2001.1649.

Pennington, M., Bowman, R. \& Langton, R. (1980). Variability of the weight of stomach contents of fish and its implications for food studies. ICES Council Meeting 1980/L:63 
Pillar, S. C. \& Barange, M. (1995). Diel feeding periodicity, daily ration and vertical migration of juvenile Cape hake off the west coast of South Africa. Journal of Fish Biology 47, 753-768.

Rindorf, A. (2002). Meal frequency and meal size of whiting (Merlangius merlangus) in the North Sea. Journal of Fish Biology 61, 579-593. doi: 10.1006/jfbi.2002.2061

Rindorf, A. (2003). Diel feeding pattern and prey choice of whiting (Merlangius merlangus) in the North Sea. Marine Ecology Progress Series 249, 265-276.

Ruohonen, K., Grove, D. J. \& McIlroy, J. T. (1997). The amount of food ingested in a single meal by rainbow trout offered chopped herring, dry and wet diets. Journal of Fish Biology 51, 93-105. doi: 10.1006/jfbi.1997.0415.

Sainsbury, K. J. (1986). Estimation of food consumption from field observations of fish feeding cycles. Journal of Fish Biology 29, 23-36.

Seyhan, K. \& Grove, D. J. (1998). Food consumption of whiting, Merlangius merlangus, in the Eastern Irish Sea. Fisheries Research 38, 233-245.

Stefánsson, G., \& Pálsson, O. K. (1997). Statistical evaluation and modelling of the stomach contents of Icelandic cod (Gadus morhua). Canadian Journal of Fisheries and Aquatic Sciences 54, 169-181.

Talbot, C., Higgins, P. J. \& Shanks, A. M. (1984). Effects of pre- and post-prandial starvation on meal size and evacuation rate of juvenile Atlantic salmon, Salmo salar L.. Journal of Fish Biology 25, 551-560.

Van Der Lingen, C. D. (1998). Gastric evacuation, feeding periodicity and daily ration of sardine Sardinops sagax in the southern Benguela upwelling ecosystem. South African Journal of Marine Science 19, 305-316. 
TABLE I. Reduced models of the weight of the different prey groups in stomachs where this weight exceeds zero. Significance levels below 0.05 are in bold writing.

\begin{tabular}{|c|c|c|c|c|c|c|}
\hline Prey group & $\begin{array}{c}\text { Whiting } \\
\text { (Merlangius } \\
\text { merlangus) }\end{array}$ & Krill & Shrimps & Crabs & $\begin{array}{c}\text { Other } \\
\text { benthic } \\
\text { invertebrates }\end{array}$ & $\begin{array}{c}\text { Other } \\
\text { crustaceans }\end{array}$ \\
\hline \multicolumn{7}{|l|}{ Model summary } \\
\hline Total deviance & 283.3 & 760.6 & 1299.1 & 1589.0 & 2039.1 & 2174.2 \\
\hline $\mathrm{R}^{2 \mathrm{a}}$ & 0.04 & 0.255 & 0.569 & 0.227 & 0.096 & 0.141 \\
\hline Dimension $^{\mathrm{b}}$ & 5 & 22 & 17 & 32 & 8 & 12 \\
\hline Scale & 2.08 & 1.00 & 1.10 & 0.44 & 0.33 & 0.49 \\
\hline Number of observations & 295 & 618 & 503 & 809 & 967 & 1467 \\
\hline \multirow[t]{2}{*}{ Locations included } & 3 and $5^{c}$ & $1,2,3$ and $4^{\mathrm{c}}$ & 1,2 and 5 & $1,2,3$ and 4 & all & $\mathrm{all}^{\mathrm{c}}$ \\
\hline & $\mathrm{P}>\mathrm{F}$ & $\mathrm{P}>\mathrm{F}$ & $\mathrm{P}>\mathrm{F}$ & $\mathrm{P}>\mathrm{F}$ & $\mathrm{P}>\mathrm{F}$ & $\mathrm{P}>\mathrm{F}$ \\
\hline$a_{l o c}$ & 0.4670 & $<0.0001$ & $<0.0001$ & $<0.0001$ & 0.2872 & $<0.0001$ \\
\hline$b_{t}$ & 0.6025 & 0.5524 & 0.0216 & 0.0016 & 0.0008 & $<0.0001$ \\
\hline$c_{l}$ & 0.5871 & 0.2773 & 0.3085 & $<0.0001$ & $<0.0001$ & 0.0080 \\
\hline$a b_{l o c, t}$ & 0.0432 & 0.0312 & $<0.0001$ & 0.0002 & 0.5586 & 0.3419 \\
\hline$a c_{l o c, l}$ & 0.4348 & 0.2734 & 0.2773 & $<0.0001$ & 0.2119 & 0.8844 \\
\hline$b c_{t, l}$ & 0.1087 & 0.2525 & 0.8495 & 0.4174 & 0.7072 & 0.27 \\
\hline
\end{tabular}

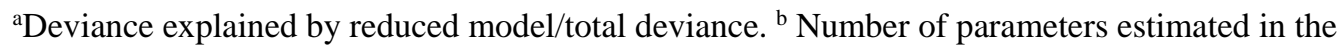

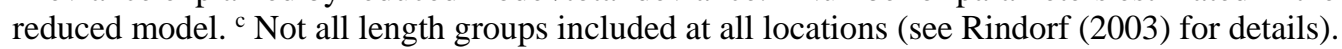


TABLE II. The number of observations, average and standard error of the mean (in parenthesis) of $\rho$ and $\rho_{L T}$.

\begin{tabular}{lcccccc}
\hline & & & & & \\
Prey group & $\mathrm{n}$ & Method Ia & $\mathrm{n}$ & Method Ib & $\mathrm{n}$ & Method II \\
\hline Whiting & 15 & $0.20(0.04)$ & 5 & $0.32(0.07)$ & 5 & $0.34(0.05)$ \\
Krill & 16 & $0.05(0.01)$ & 7 & $0.07(0.02)$ & 10 & $0.10(0.02)$ \\
Shrimp & 6 & $0.08(0.03)$ & 3 & $0.14(0.04)$ & 3 & $0.16(0.05)$ \\
Crab & 35 & $0.11(0.01)$ & 12 & $0.19(0.02)$ & 6 & $0.09(0.01)$ \\
Other benthic invertebrates & 42 & $0.093(0.007)$ & 15 & $0.13(0.01)$ & 15 & $0.121(0.008)$ \\
Other crustaceans & 37 & $0.055(0.006)$ & 11 & $0.08(0.01)$ & 9 & $0.15(0.03)$ \\
& & & & & & \\
Prey group & & & & & $10^{3} \rho_{L T}$ & \\
Whiting & $\mathrm{n}$ & Method Ia & $\mathrm{n}$ & Method Ib & $\mathrm{n}$ & Method II \\
Krill & 15 & $0.86(0.17)$ & 5 & $1.34(0.25)$ & 5 & $1.45(0.09)$ \\
Shrimp & 16 & $0.17(0.03)$ & 7 & $0.24(0.05)$ & 10 & $0.31(0.04)$ \\
Crab & 6 & $0.28(0.11)$ & 3 & $0.46(0.18)$ & 3 & $0.55(0.27)$ \\
Other benthic invertebrates & 33 & $0.39(0.06)$ & 12 & $0.67(0.10)$ & 6 & $0.32(0.04)$ \\
Other crustaceans & 42 & $0.32(0.02)$ & 15 & $0.42(0.01)$ & 15 & $0.42(0.02)$ \\
\hline
\end{tabular}


TABLE III. Analyses of $\rho$ as a function of temperature and length of the predator in the prey groups where 10 or more estimates of $\rho$ could be calculated. Parameter estimates significant at the $5 \%$ level are in bold writing and values in parathesis indicate standard error of the mean.

\begin{tabular}{|c|c|c|c|c|c|}
\hline & $\mathrm{n}$ & $\mathrm{r}^{2}$ & $\lambda$ & $\delta^{1}$ & $\delta_{\text {Prey }}$ \\
\hline Method Ia & 38 & 0.65 & $1.21(0.38)$ & $-0.061(0.047)$ & \\
\hline $\mathrm{P}$ (same for all prey) & & & 0.5401 & 0.0386 & \\
\hline Crab & & & & & $-0.12(0.03)$ \\
\hline Other benthic invertebrates & & & & & $-0.01(0.03)$ \\
\hline Other crustaceans & & & & & $-0.06(0.05)$ \\
\hline Method Ib & 38 & 0.74 & $1.48(0.29)$ & $-0.021(0.02)$ & \\
\hline $\mathrm{P}$ (same for all prey) & & & 0.6618 & 0.0003 & \\
\hline Crab & & & & & $-0.10(0.02)$ \\
\hline Other benthic invertebrates & & & & & $0.048(0.022)$ \\
\hline Other crustaceans & & & & & $-0.04(0.04)$ \\
\hline Method II & 25 & 0.66 & $0.61(0.39)$ & $0.079(0.020)$ & \\
\hline P(same for both prey) & & & 0.2535 & 0.0177 & \\
\hline Krill & & & & & $0.14(0.03)$ \\
\hline Other benthic invertebrates & & & & & $0.042(0.023)$ \\
\hline
\end{tabular}

${ }^{1}$ Estimated common temperature effect of all prey. 
TABLE IV. Literature estimates of $\rho_{L T}$ calculated from the relationship $\rho_{L T}=0.00128 E^{-}$ ${ }^{0.86}$, where $E$ is energy density in $\mathrm{Kjg}^{-1}$ (Andersen 2001).

\begin{tabular}{lccc}
\hline Prey group & $E$ & $10^{3} \rho_{\text {LT }}$ & Source \\
\hline Whiting & 3.7 & 0.42 & Pedersen \& Hislop, 2001 \\
Krill & 4.0 & 0.39 & Andersen, 1999; 2001 \\
Shrimp & & $0.21^{1}$ & Andersen, 1999 \\
Nereis and Nephtys (polychaeta) & $<4.9^{2}$ & $>0.33$ & Jones, 1974; Pedersen \& Hislop, 2001 \\
A. marina (polychaeta) & 2.5 & 0.58 & Dos Santos \& Jobling, 1995 \\
\hline
\end{tabular}

${ }^{1}$ Given directly in the source

${ }^{2}$ Greater than the evacuation rate of saithe (Pollachius virens) for which the average energy density is $E=4.9$. 
FIG 1. Illustration of method II. A: Change in occurrence of 'other benthic invertebrates' at location 2 (predator length 25-30 cm) around the clock. The maximum drop in occurrence is found from 1100 hours to 1500 hours and amounts to 45\%. B: The cumulated distribution of weight of 'other benthic invertebrates' in the stomachs at 1100 hours (predator length $25-30 \mathrm{~cm}$ ). Each data point represents the cumulated weight distribution calculated in $0.1 \mathrm{~g}$ intervals. $45 \%$ of the stomachs in which 'other benthic invertebrates' were found contained less than $0.288 \mathrm{~g}$ of this prey. A total of 120 stomachs sampled from this length group at location 2 at 1100 hours contained 'other benthic invertebrates'.

FIG 2. Comparison of diel patterns in occurrence of each prey at the five locations. Location 1: $\diamond$. Location 2: $\boldsymbol{\square}$. Location 3: $\boldsymbol{\Delta}$. Location 4: O. Location 5: ×. A: 'Whiting’. B: ‘Krill’. C: ‘Shrimps’. D: ‘Crabs’. E: 'Other benthic invertebrates’. F: ‘Other crustaceans'. Predator length $25-30 \mathrm{~cm}$. Shaded areas indicate night periods. From Rindorf (2003). Reproduced with permission from the publisher.

FIG 3. Observed total weight of the prey in stomachs containing the prey $(\diamond)$, reduced model estimates of this (-) and 95\% confidence limits of the estimate $\left({ }^{---}\right)$as a function of time of day. A: 'Whiting' (location 5). B: 'Crabs' (location 3). C: 'Other benthic invertebrates’ (all locations). Predator length 20-35 cm. Shaded areas indicate night periods.

FIG 4. Comparison of diurnal patterns in model estimates of the average weight of a prey present in a stomach given the prey was present. Location 1: $\diamond$. Location 2: Location 3: A. Location 4: O. Location 5: ×. A: 'Whiting’. B: 'Krill'. C: 'Shrimps'. 
D: ‘Crabs’. E: ‘Other benthic invertebrates’ (No difference between locations). F: 'Other crustaceans'. Predator length 25-30 cm.

FIG 5. $S_{t+4}^{0.5}$ as a function of $S_{t}^{0.5}$, both calculated by method Ia. Only periods during which $S_{t}^{0.5}$ exceeds $S_{t+4}^{0.5}$ are included. Predator length 20-25 cm ( $\left.\square\right), 25-30 \mathrm{~cm}(\diamond)$, 30-35 $\mathrm{cm}(\Delta)$ and all lengths together $(\diamond)$. Hatched line is proportionality with the indicated values of $\rho$ and a lack of fit of the line indicates lack of fit of the square root evacuation model to the data. $\rho$ was calculated as the average of the values estimated for each position and size groups. A: 'Whiting’. B: ‘Krill’. C: 'Shrimps’. D: 'Crabs’. E: 'Other benthic invertebrates’. F: 'Other crustaceans'.

FIG 6. Estimates of $\rho$ as a function of temperature for the prey groups 'krill' (A, B and C), ‘crabs’ (D, E and F), ‘other benthic invertebrates’ (G, H and I) and ‘other crustaceans' (J, K and L). Predator length 20-25 cm (left panel), 25-30 cm (middle panel) and 30-35 cm (right panel). $\rho$ calculated by method Ia $(\triangle)$, Ib (*) and II ( $\square)$. Vertical bars indicate the range of estimates obtained by assuming the percentage

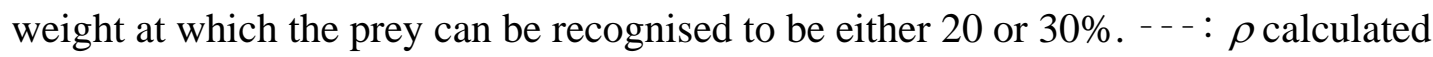
by eq. 5 ( $\rho_{L T}$ estimated by method Ia (Table II)).

FIG 7. Estimates of $\rho$ as a function of temperature for 'shrimps' (A) (No significant difference between predator length groups) and as a function of predator length for 'whiting' at location $5\left(8.6^{\circ} \mathrm{C}\right)(\mathrm{B})$ and $3\left(10.6{ }^{\circ} \mathrm{C}\right)(\mathrm{C}) . \rho$ calculated by method Ia $(\triangle)$, Ib (*) and II ( $\square)$. Vertical bars indicate the range of estimates obtained by 
assuming the percentage weight at which the prey can be recognised to be either 20 or 30\%. - - : $\rho$ calculated by eq. 5 ( $\rho_{\text {LT }}$ estimated by method Ia (Table II)).

FIG 8. Bias in estimated $\rho$. A: Bias introduced by using mean weights as a function of the proportion of stomachs in which the prey is still recognizable after a four hour period. 'Whiting' $(+)$, 'krill’ $(\square)$, 'shrimps’ $(\triangle)$, 'crabs’ $(\times)$, 'other crustaceans’ $(\diamond)$, 'other benthic invertebrates’ $(\boldsymbol{\square})$ and regression on all prey $\left(^{---}\right)$. B: Bias introduced by other food in the stomach as a function of weight of prey in percentage of the total stomach content (calculated from eq. 7). C: Mean bias introduced by other food in the stomach for the prey groups ‘whiting' (a), 'krill’ (b), 'shrimps’ (c), ‘crabs’ (d), 'other benthic invertebrates’ (e) and 'other crustaceans’ (f). Locations 1 ( $\square), 2(\square), 3(\square), 4$ $(\mathbb{\mathbb { N }})$ and $5($ 目). 

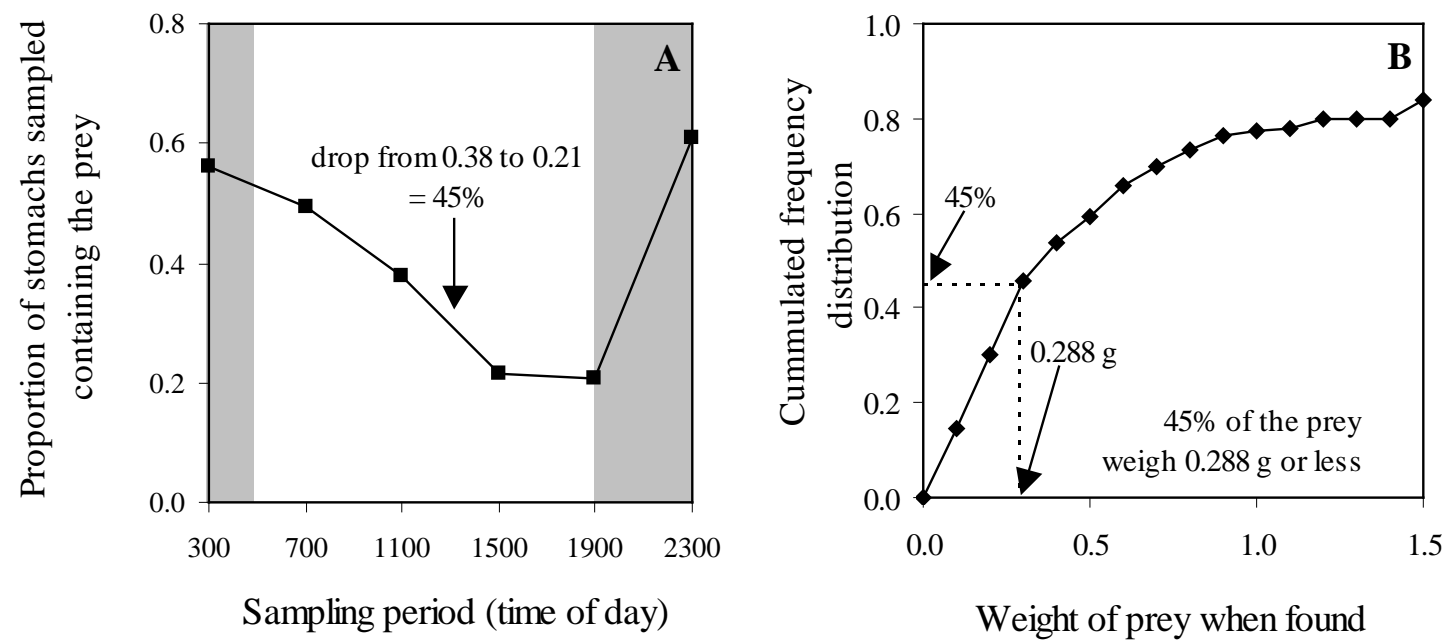

Fig. 1 

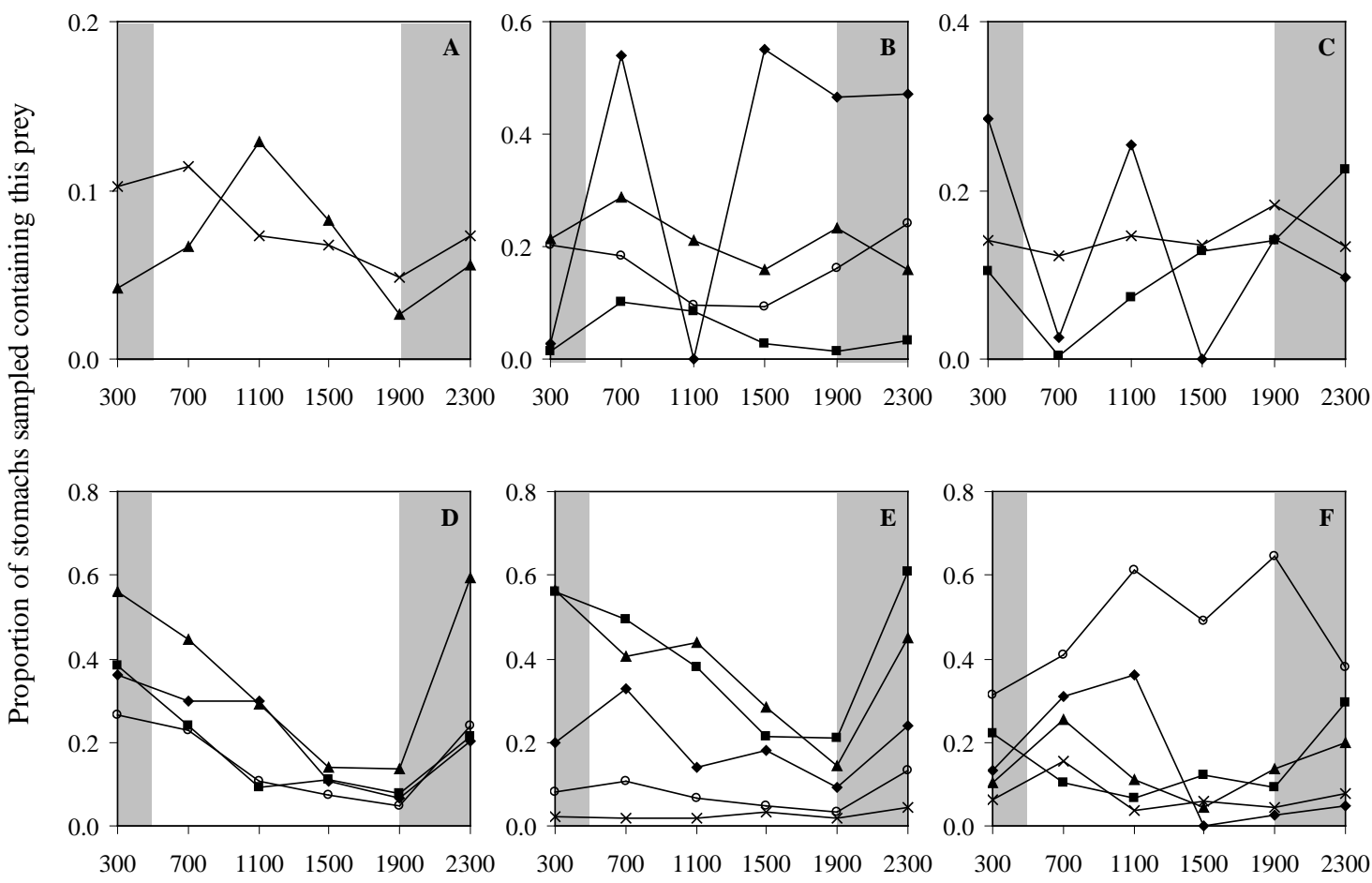

Sampling period (time of day)

Fig. 2 

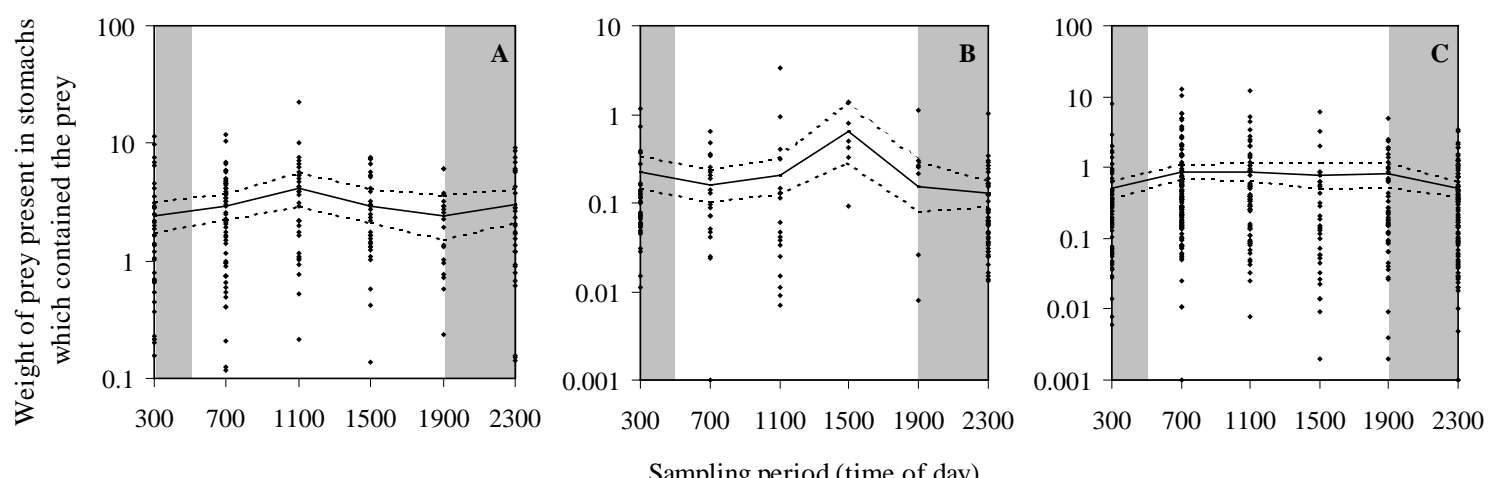

Fig. 3 


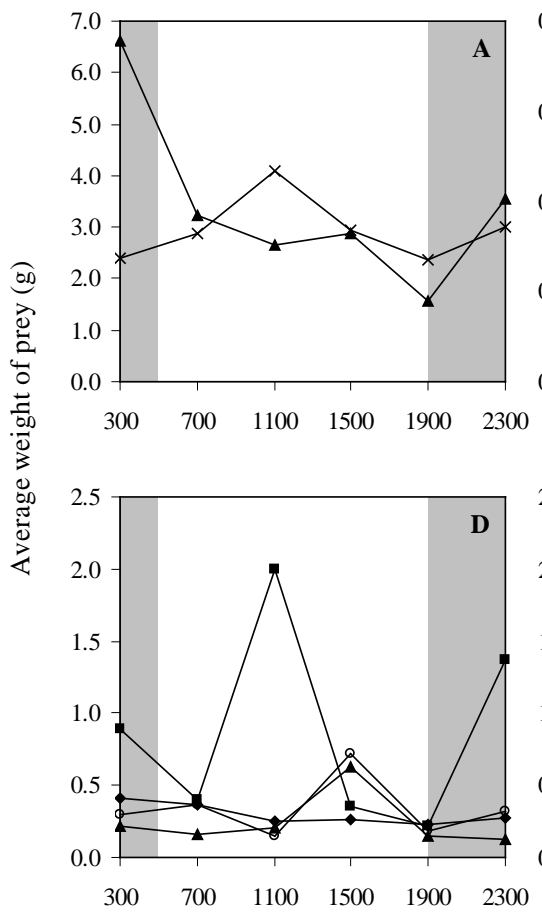

$\begin{array}{llllll}300 & 700 & 1100 & 1500 & 1900 & 2300\end{array}$
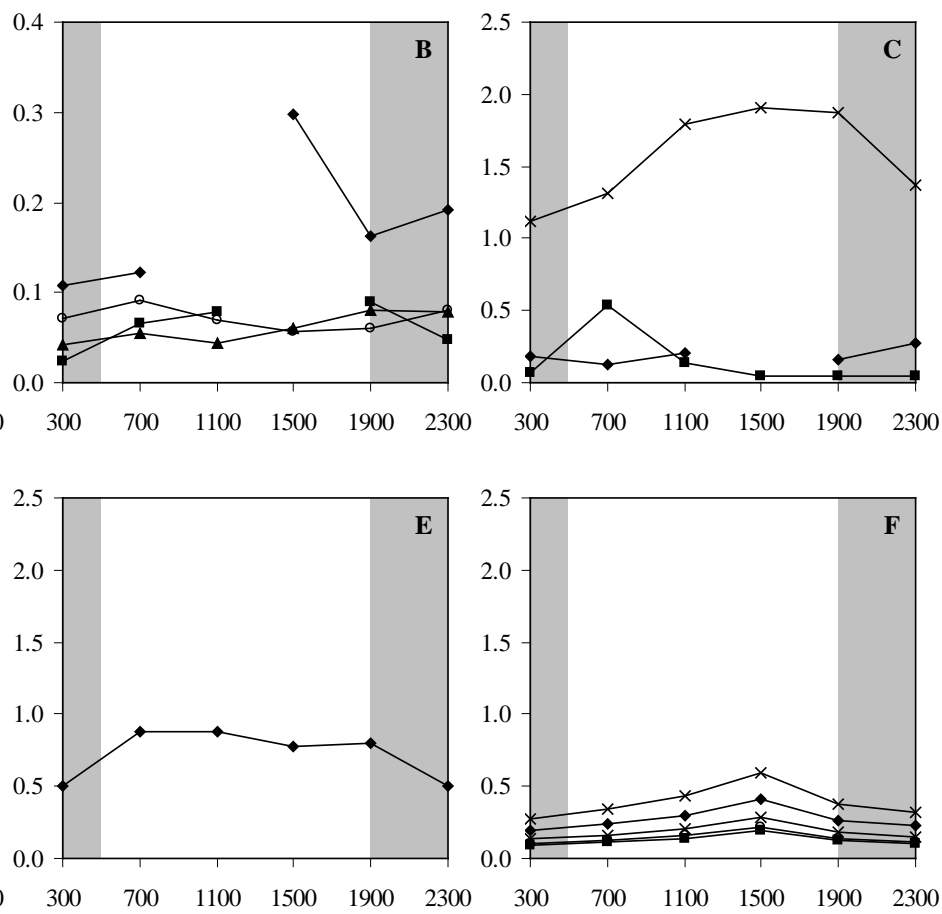

Sampling period (time of day)

Fig. 4 

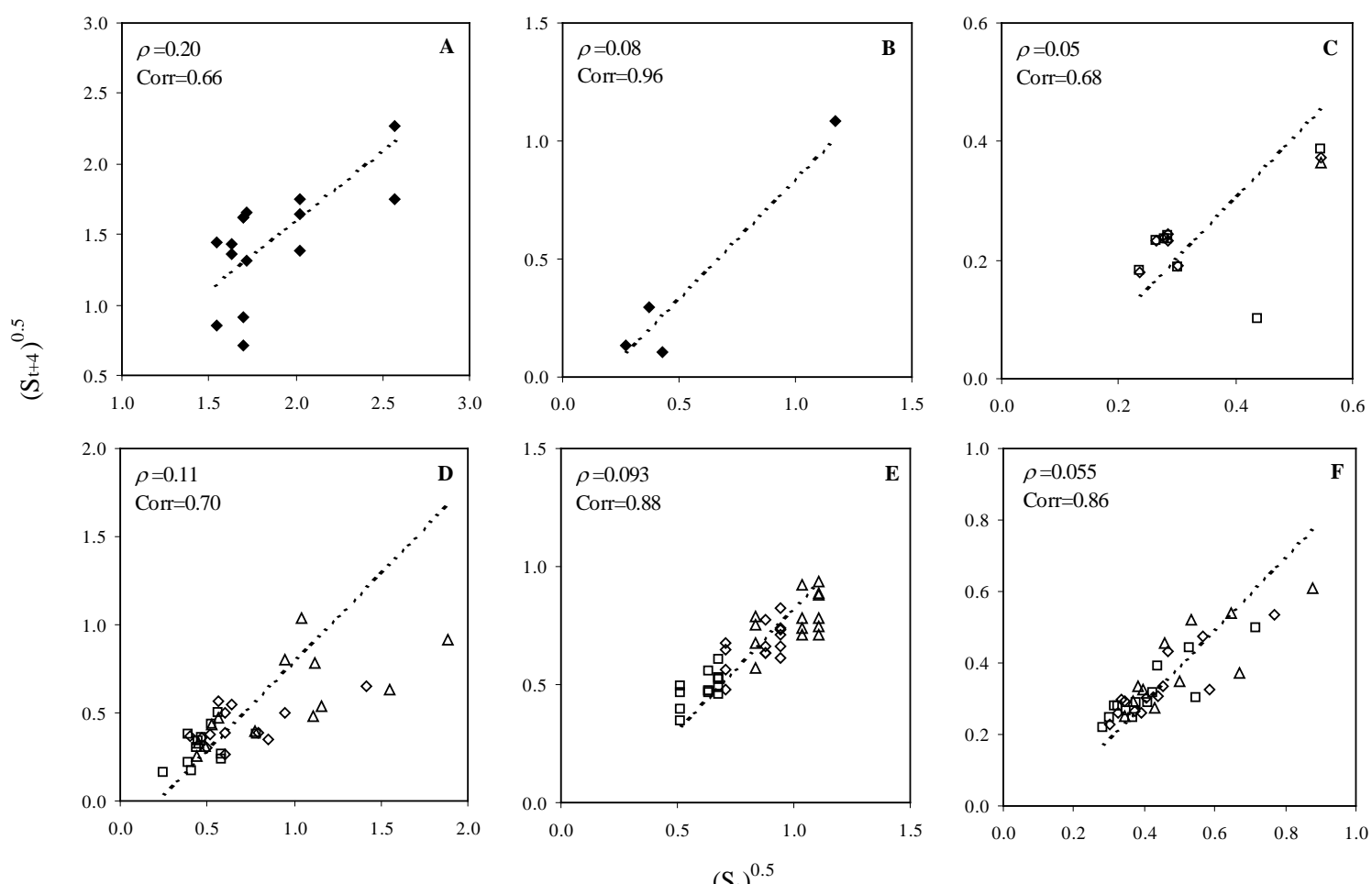

Fig. 5 

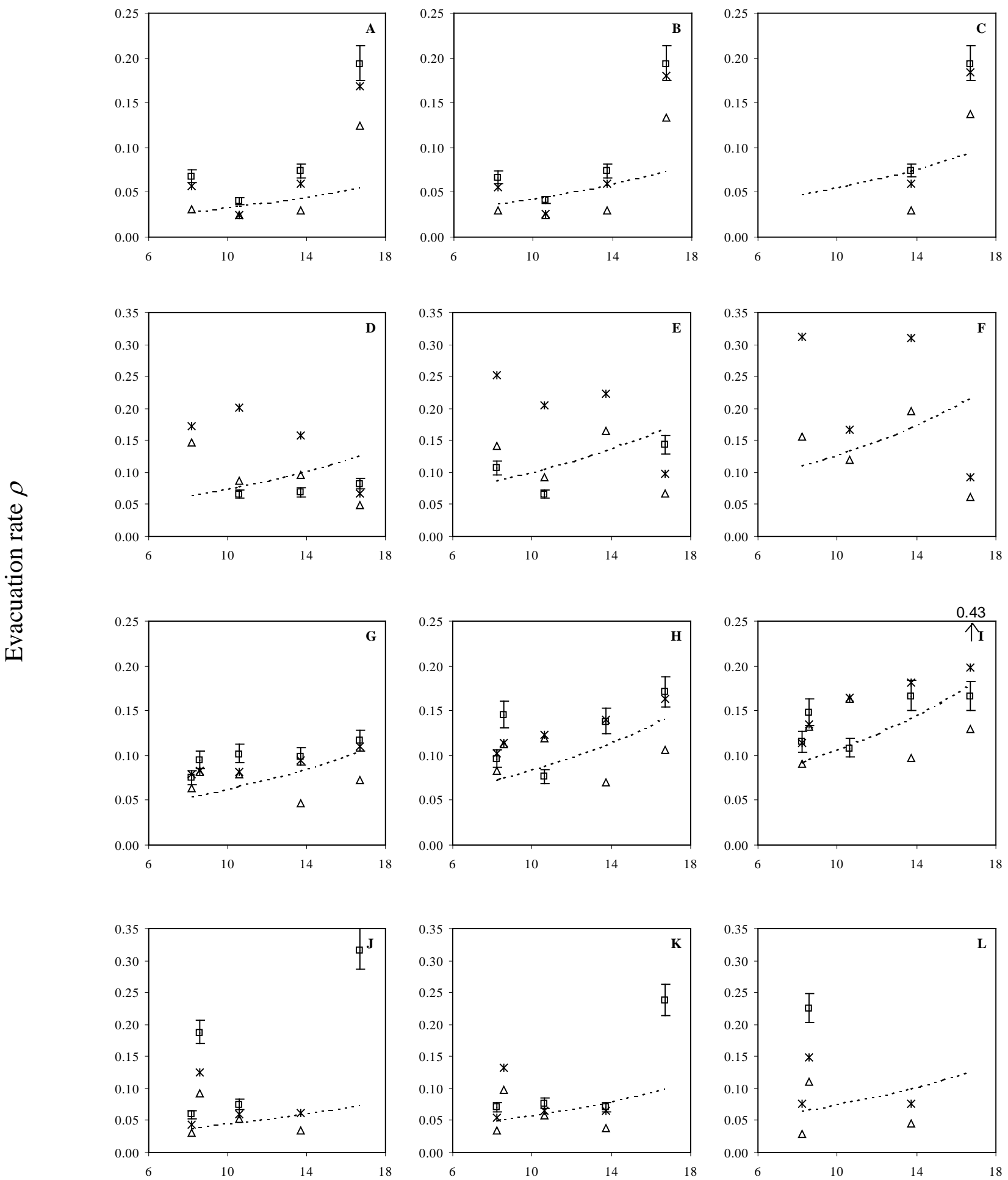

Temperature $\left({ }^{\circ} \mathrm{C}\right)$

Fig. 6 

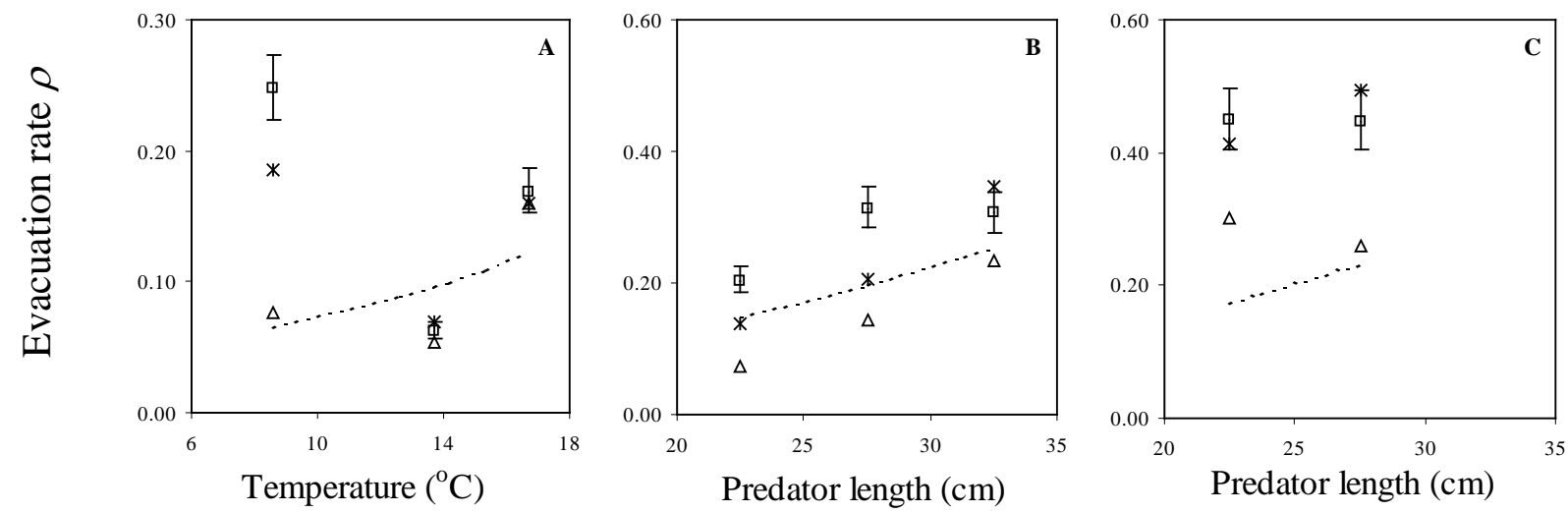

Fig. 7 


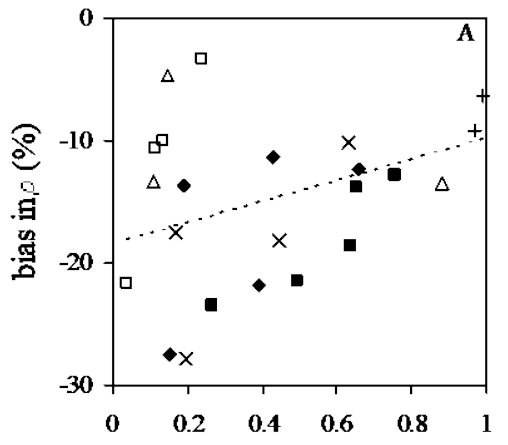

Proportion of prey recognizable

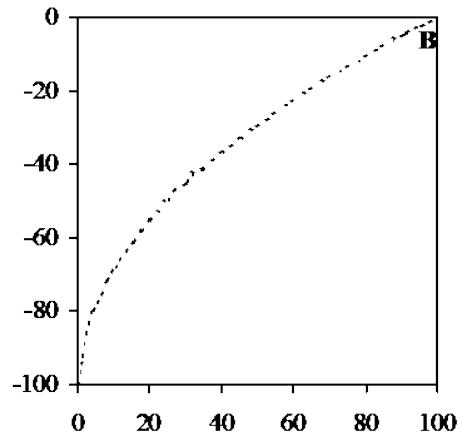

Weight of prey in per cent of total

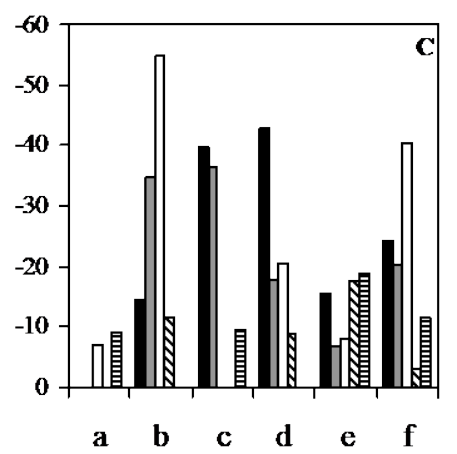

$\begin{array}{llllll}a & b & c & d & e & f\end{array}$

Fig. 8 